\title{
AVALIAÇÃO COPROPARASITOLÓGICA E CLÍNICA DE AVES SILVESTRES E EXÓTICAS MANTIDAS EM CRIATÓRIOS PARTICULARES NO MUNICÍPIO DE ALEGRE-ES
}

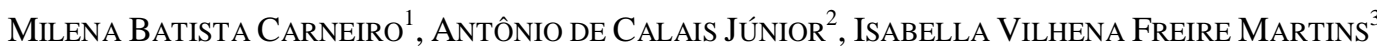 \\ ${ }^{1}$ Doutoranda em Parasitologia Veterinária na Universidade Federal Rural do Rio de Janeiro - \\ milenabatistacarneiro@hotmail.com \\ ${ }^{2}$ Residente em Patologia Animal no Centro Universitário Vila Velha - UVV. \\ ${ }^{3}$ Professora Doutora da Universidade Federal do Espírito Santo
}

\begin{abstract}
Objetivou-se traçar o perfil coproparasitológico e avaliar clinicamente aves silvestres e exóticas de criadores particulares de Alegre, ES. Foram examinados 36 pássaros distribuídos entre 25 coleiros, 08 trinca-ferros, 01 calopsita, 01 canário belga e 01 azulão. Das 36 aves examinadas, 14 (38,89\%) apresentaram diagnóstico positivo para parasitose. Dos 25 coleiros examinados, 06 (24\%) foram positivos para coccídios e 01 (4\%) positivo para coccídios e ovos do tipo Strongyloidea. Dos 08 trinca-ferros, 04 (50\%) foram positivos para coccídios e 02 (25\%) foram positivos para coccídio e Giardia. A calopsita apresentou resultado positivo para coccídio e Giardia e o canário belga e azulão apresentaram

resultados negativos para parasitos intestinais. Dos 25 animais examinados fisicamente, foram observados 06 animais com onicogrifose (24\%), 03 animais com descamação de pele (12\%), 02 animais obesos (8\%), 01 animal magro (4\%), 01 animal com diarréia (4\%) e 01 animal com sinais respiratórios (4\%). Com o perfil coproparasitológico foi possível verificar uma alta frequência de parasitoses nos pássaros examinados sem haver necessariamente sintomatologia clínica associada. A carência de profissionais especializados na área de animais silvestres e exóticos no município dificulta a realização de exames mais específicos e de orientações mais detalhadas sobre o manejo de determinadas aves.
\end{abstract}

RESUMO

PALAVRAS-CHAVE: exame coproparasitológico; avaliação clínica; ave silvestre; ave exótica.

\section{COPROPARASITOLOGICAL AND CLINICAL EVALUATION OF PARTICULAR BIRDS IN ALEGRE-ES, BRAZIL}

\begin{abstract}
The objective of this study was to identify the gastrointestinal parasites and to carry out a clinical evaluation of particular birds of Alegre, ES, Brazil. Of the 36 examined birds, 14 (38.89\%) were positive. Of the 25 examined Sporophila caerulescen, six (24\%) were positive for coccidia and one (4\%) for coccidia and Strongyloidea. Of eight Saltator similis, four (50\%) were positive for coccídios and two (25\%) for coccidia and Giardia. The Nymphicus hollandicus presented coccidia and Giardia and both Serinus canaria and Passerina
\end{abstract}

brissonii were negative. Of the 25 examined animals the physical alterations were: six birds with big nails (24\%), three animals with skin descamation (12\%), two fat birds (8\%), one thin bird (4\%), one animal with diarrhea (4\%) and an animal presented cough signals and sneeze (4\%). The study showed a high frequency of parasites in the birds without clinical signs. The lack of specialized professionals in the area of wild animals in Alegre, ES makes difficult specific examinations and detailed orientations on birds handling.

KEYWORDS: clinical evaluation; wild bird; exotic bird. 


\section{INTRODUÇÃO}

Entre os numerosos problemas sanitários que afetam as aves silvestres e exóticas mantidas em cativeiro, as enfermidades parasitárias se destacam como uma das mais frequentes, e os efeitos que produzem variam de infecções subclínicas ao óbito. As aves silvestres são hospedeiras de uma grande variedade de parasitos, mas existem poucos trabalhos sobre as espécies que acometem esses animais em cativeiro e os trabalhos existentes referem-se a grupos reduzidos de aves (FREITAS et al., 2002).

De acordo com MARIETTO-GONÇALVES et al. (2009), aves silvestres e exóticas podem ser parasitadas por ovos de Ascaridia spp., Heterakis spp. e Tricurídeos, cistos de Balantidium spp., Blastocystis spp. e Entamoeba spp. e oocistos de Coccídeos, sendo que estes últimos são as estruturas parasitárias mais encontradas, principalmente na ordem Passeriformes. Parasitismos por Giardia, Ascaridia e coccídeos se destacam entre as de maior ocorrência em aves psitaciformes (TSAI et al., 1992; BARTON et al., 2003; KAJEROVA \& BARUS, 2005).

Além destas, a criptosporidiose é considerada a mais prevalente infecção parasitaria em aves domésticas, de gaiolas e pássaros silvestres, sendo caracterizada como problema emergente para a indústria avícola mundial (DILLINGHAM et al., 2002). Pode causar tanto infecções respiratórias, como entéricas (O'DONOGHUE, 1995; STRETER \& VARGA, 2000).

A coccidiose, muito comum em aves, é uma doença parasitária causada por protozoário da classe Coccidia, destacando-se os genêros Eimeria e Isospora, por serem parasitas tanto de animais domésticos como selvagens, causando-lhes enfermidades persistentes principalmente quando criados em confinamento. Apenas 13 espécies do gênero Isospora foram identificadas parasitando pássaros (UPCROFT et al., 1997). SILVA et al. (2009) caracterizaram o gênero Isospora como o gênero frequente em psitacídeos.

Qualquer fator que comprometa as defesas orgânicas de um pássaro com coccidiose assintomática poderá levá-lo à manifestação de um quadro agudo de coccidiose (SOULSBY, 1986). A transmissão da doença ocorre por meio de oocistos eliminados com as fezes e a urina, contaminando os alimentos, a água e o meio ambiente (BENEZ, 1993; THADEI, 2007). Os sinais incluem: penas arrepiadas, sonolência, perda do apetite ou apetite exagerado, diarréia, fraqueza, perda de peso, caquexia ("peito seco"), apatia e prostração. Também podem ser observados problemas reprodutivos, problemas de pele e de muda atrasada de penas (BENEZ, 2007).

Outra doença parasitária de grande importância em aves mantidas em cativeiro é a giardíase, causada por um protozoário do gênero Giardia. O cisto é a forma infectante para homens e animais (LLOYD et al., 2002), que se infectam por contato direto e ingestão de água e alimento contaminados (THOMPSON, 2000). A Organização Pan-Americana de Saúde (PAHO) considera a giardíase uma doença zoonótica cosmopolita de potencial epidêmico (ACHA et al., 2003). É considerada doença comum e importante em psitacídeos (McDONNELL et al., 2003), tendo como sinal clínico mais comum a diarréia. Alterações cutâneas também podem surgir, como pele seca, prurido e automutilação. Apesar de ser relativamente comum em psitacídeos, a giardíase é considerada rara em outros pássaros em cativeiro (RUPLEY, 2000).

A prevenção dessas parasitoses está ligada aos cuidados gerais de higiene na criação, alimentação balanceada, água de boa qualidade, regras de manejo adequado ao tipo de criação, treinamento dos tratadores nos cuidados com o manuseio das aves doentes, exames periódicos de fezes e realização de exames laboratoriais no caso de morte no plantel (SCHARRA, 2007).

Objetivou-se com este trabalho traçar a relação entre o perfil coproparasitológico e sintomatologia clínica de pássaros silvestres e exóticos de criadores particulares na cidade de Alegre, ES.

\section{MATERIAL E MÉTODOS}

No período de 03 de maio de 2007 a 06 de junho de 2007, foram realizados exames físicos e coproparasitológicos em 36 pássaros de criadores particulares da cidade de Alegre- ES, sendo 25 coleiros (Sporophila caerulescens), 08 trinca-ferros (Saltator similis), 01 calopsita (Nymphicus hollandicus), 01 canário belga (Serinus canaria) e 01 azulão (Passerina brissonii). Todos os animais estavam instalados em gaiolas.

Antes da realização do exame físico foi realizada anamnese e exame geral da gaiola observando o comportamento do animal. Posteriormente, as aves foram contidas fisicamente e, após anotação do número de registro observado na anilha, foram verificados os parâmetros clínicos. Alguns animais não foram examinados clinicamente por receio de seus proprietários.

As fezes foram coletadas forrando-se o fundo da gaiola com papel alumínio colocado no fundo da gaiola um dia antes da realização do exame. As amostras fecais foram mantidas sob refrigeração e 
encaminhadas ao Hospital Veterinário do Centro de Ciências Agrárias da Universidade Federal do Espírito Santo (HOVET- CCA/UFES). Foi realizada a Técnica de Faust com solução de sulfato de zinco a 33\% (FAUST, 1938) ${ }^{17}$, indicada para o diagnóstico dos protozoários do gênero Giardia, além de facilitar a identificação de outros protozoários e permitir a observação de ovos de helmintos. A coleta de fezes foi realizada uma única vez para cada animal.

Após todas as análises laboratoriais, foi elaborado um laudo para cada proprietário indicando o tratamento adequado para cada caso e orientações de manejo, incluindo controle de doenças.

Foi realizada análise através de estatística descritiva, calculando-se a frequência de parasitoses presentes nas aves.

\section{RESULTADOS E DISCUSSÃO}

Das 36 aves examinadas, 14 (38,89\%) apresentaram diagnóstico positivo nos exames coproparasitológicos. Dos 25 coleiros examinados, seis (24\%) animais foram positivos para coccídios e um (4\%) foi positivo para coccídios e ovos do tipo Strongyloidea e nenhum positivo para Giardia. Dos oito trinca-ferros, quatro (50\%) foram positivos para coccídios e dois (25\%) foram positivos para coccídio e Giardia. A calopsita apresentou resultado positivo para coccídio e Giardia e o canário belga e azulão apresentaram resultados negativos (Tabela 1).

Tabela 1. Frequência de infecções parasitárias em pássaros de criadores particulares de Alegre-ES.

\begin{tabular}{ccccc}
\hline & $\begin{array}{c}\text { Número total } \\
\text { de amostras }\end{array}$ & $\begin{array}{c}\text { Amostras } \\
\text { positivas para } \\
\text { coccídio }\end{array}$ & $\begin{array}{c}\text { Amostras positivas } \\
\text { para coccídio e } \\
\text { Giardia }\end{array}$ & $\begin{array}{c}\text { Amostras positivas para } \\
\text { coccídio e Strongyloidea }\end{array}$ \\
\hline Sporophila caerulescens & 25 & $6(24 \%)$ & 0 & $1(4 \%)$ \\
Saltator similis & 8 & $4(50 \%)$ & $2(25 \%)$ & 0 \\
Nymphicus hollandicus & 1 & 0 & $1(100 \%)$ & 0 \\
Serinus canaria & 1 & 0 & 0 & 0 \\
Passerina brissonii & 1 & 0 & 0 & 0 \\
\hline
\end{tabular}

BURBANO et al. (2003), em estudo com 88 psitacídeos na Colômbia, relataram prevalência de 6\% de Isospora em aves criadas em cativeiro, dado que difere do encontrado neste estudo. Esses resultados podem ter diferido por diversos fatores: 0 fato de serem psitacídeos e não passeriformes, as condições diferentes de manejo das aves, a condição física das aves, a contaminação dos alimentos e água oferecidos às aves, entre outros. GOLÇALVES et al. (2006), em artigo sobre endoparasitos de aves silvestres, relataram que $95,45 \%$ das amostras positivas para coccidios foram provenientes de passeriformes.

Com relação às outras parasitoses, relatam-se frequência de 2,12\% de Giardia em aves silvestres (CARBONERA et al., 1997), dados que diferem daqueles presentes neste estudo. Foi confimada a presença de Giardia em corvos necropsiados no Egito, correlacionando-a com um surto de diarréia humana, incriminando a contaminação ambiental por cistos eliminados por estes pássaros como possível causa do aumento do número dos casos de diarréia na população (Al-SALLAMI, 1991).

Após análise comparativa com os exames clínicos, constatou-se que as aves estudadas são deslocadas do plantel apenas durante os dias de torneio, não apresentando nenhum sinal de doença clínica relacionada a essas protozooses e nem apresentando nenhuma outra patologia.

Do total de 36 animais, 25 foram examinados clinicamente por receio dos proprietários em realização da contenção. Dos 25 animais examinados fisicamente, as alterações observadas foram: seis animais com onicogrifose (24\%); três animais com descamação de pele, principalmente da região peitoral (12\%); dois animais obesos (8\%); um animal magro (4\%); um animal com diarréia (4\%); e um animal apresentou sinais de tosse e espirro (4\%).

Deve-se relacionar o resultado do exame coproparasitológico com o estado físico do animal. Nenhum animal apresentou um problema grave de saúde, porém, as aves que demonstraram alta infecção por oocistos de coccídios foram encaminhadas para tratamento antiparasitário, pois, como estavam na época da muda, poderiam, em algum momento, apresentar sintomatologia. Nesse caso, foi recomendado o uso de sulfamidinas na dose descrita pelo fabricante. Além disso, foi recomendado o fornecimento de água tratada e higienização das frutas em água filtrada para evitar contaminação por essa via.

Nos animais positivos para Giardia foi 
indicado o tratamento com metronidazol na dose de 0,65 mL para $200 \mathrm{~mL}$ de água e a utilização de água filtrada para beber e para limpeza das frutas.

Para as aves que apresentaram descamação de pele foi recomendada a administração de vitamina A assim como fornecimento variado de frutas. Nos animais obesos, os proprietários foram orientados a diminuir o fornecimento de algumas sementes até a recuperação do peso. Ao contrário, para a ave caquética, foi recomendado o fornecimento de sementes e frutas variadas. Os animais com tosse/ espirro e diarréia ficaram sob observação dos proprietários, pois os sintomas não eram frequentes.

Como melhoria nas técnicas de manejo foi recomendada a lavagem periódica das gaiolas com sabão neutro, secando-as ao sol; lavagem diária dos bebedouros e comedouros com sabão neutro e, se possível, deixar os vasilhames de molho em água sanitária diluída em água; limpeza diária do fundo da gaiola; fornecimento de frutas variadas para todas as espécies; exposição dos animais ao sol durante a manhã e final da tarde; evitar colocar frutas, bebedouros e comedouros sob os poleiros para que não haja contaminação dos alimentos e realização de exame coproparasitológico periodicamente.

Durante a realização deste trabalho, nem todos os animais que apresentaram resultado positivo para coccídios receberam tratamento, pois a presença de oocistos no trato gastrointestinal de pássaros é comum, sendo até aconselhável que se tenha certas quantidades de oocistos para que a ave, quando exposta à contaminação por esse protozoário, não manifeste a doença.

Foi possível relatar que nenhum proprietário havia feito qualquer exame nos seus pássaros anteriomente, tanto pela falta de informação sobre a importância de acompanhamento de um profissional da área, como o médico veterinário, quanto para evitar o uso indiscriminado de vitaminas, minerais e medicações, o que pode acarretar problemas sérios de saúde das aves quando feito sem orientação. E todos os proprietários já haviam usado em determinada época de vida da ave alguma medicação.

No entanto, a participação de pássaros em cativeiro como reservatórios e eliminadores do agente para o meio ambiente merece um estudo mais detalhado. Reforça essa idéia a falta de educação sanitária por parte dos criadores de pássaros, que, em sua maioria, não procura assistência veterinária, tão pouco realiza exames coproparasitológicos em seus plantéis. Esses fatos, aliados ao descarte de dejetos oriundos da criação no meio ambiente, provavelmente contribuem para a contaminação ambiental, com eventuais implicações econômicas e zoonóticas.

\section{CONCLUSÕES}

A partir do perfil coproparasitológico foi possível verificar uma alta frequência de parasitoses nos pássaros silvestres e exóticos mantidos em criatórios particulares no município de Alegre-ES, especialmente coccidiose, o que não necessariamente caracteriza a presença de sintomatologia clínica.

\section{REFERÊNCIAS}

ACHA, P.N.; SZYFRES, B. Zoonoses and Communicable Diseases common to Man and Animals. 3.ed., v.3, 2003, p. 52-58.

Al-SALLAMI, S. A possible role of crows in the spread of diarrhoeal diseases in Aden. The Journal of the Egyptian Public Health Association, v. 66, n. 3-4, p. 441-449, 1991.

BARTON, C. E.; PHALEN, D. N.; SNOWDEN, K. F. Prevalence of microsporidian spores shed by asymptomatic lovebirds: Evidence for a potential emerging zoonosis. Journal of Avian Medicine and Surgery, v. 17, n. 4, p. 197-202, 2003.

BENEZ, S.M. Coccidiose em aves ornamentais. Disponível em < http://www.amgercal.com.br/>. Acesso em 10 de junho de 2007.

BENEZ, S.M. Coccidiose: Perspectivas de controle. Atualidades Ornitológicas, p. 54, 1993.

BURBANO, P.S.; ACOSTA, D.O.; MONTAÑO, J.B.; MARTINES, K. Parásitos gastrointestinales en las aves de la familia Psittacidae en la Fundación Zoológica de Cali (Cali, Valle del Cauca, Colombia). Medicina Veterinária; v. 20 (6), p. 67-72, 2003.

CARBONERA, M.; LAGAGGIO, V.R.A.; FLORES, M.L.; COLOMBO, F.H.; CIGANA, G.B. Levantamento parasitário em aves silvestres da fauna riograndense. Revista Brasileira de Parasitologia Veterinária, v. 6, p. 280, 1997.

DILLINGHAM, R.A.; LIMA, A.A.; GUERRANT, R.L. Cryptosporidiosis: epidemiology and impact. Microbes Infection, v. 89, n. 9, p. 1059-1066, 2002.

FAUST, E.C.; D’ANTONI, J. S.; ODOM, V.; MILLER, M.J.; PERES, C.; SAWITZ, W.; THOMEN, L. F,; TOBIE, J.; WALKERN, J. H. A critical study of clinical laboratory technics for the diagnosis of protozoan cysts and helminth eggs in feces I. Preliminary communication. American Journal of Tropical Medicine, v.18, p.169183, 1938.

FREITAS DE, M. F. L.; OLIVEIRA DE J. B.; CAVALCANTI, M. D. B.; LEITE, A. S. L.; MAGALHÃES, V. S.; OLIVEIRA R. A.; SOBRINO, A. E. Parásitos gastrointestinales de aves silvestres em cautiverio em el estado de Pernambuco, Brasil. Parasitologia Latinoamericana, v. 57, p. 50-54, 2002. 
GONCALVES, G.A.M.; MARTINS, T.F.; LIMA, E.T.; LOPES, R.S.; ANDREATTI FILHO, R. L. Prevalência de endoparasitas em amostras fecais de aves silvestres e exóticas examinadas no laboratório de ornitopatologia e no laboratório de enfermidades parasitárias da FMVZUNESP/Botucatu-SP. Anais do Congresso Anual da Sociedade Paulista de Zoológicos, p. 7-14, 2006.

KEJEROVA, V. e BARUS, V. Psittacine birds (Aves: Psittaciformes) as new hosts of Baruscapillaria obsignata (Nematoda: Capillariidae). Acta Veterinaria Brno, v. 74, n. 4, p. 571-574, 2005.

LLOYD, D.; HARRIS, J.C. Giardia: highly evolved parasite or early branching eukaryote? Trends in Microbiology, v. 10, p. 122-127, 2002.

MARIETTO-GONÇALVES, G. A.; MARTINS, T. F.; LIMA, E. T.; LOPES, R. S.; ANDREATTI FILHO, R. L. Prevalência de endoparasitas em amostras fecais de aves silvestres e exóticas examinadas no Laboratório de Ornitopatologia e no laboratório de Enfermidades Parasitárias da FMVZ-UNESP/Botucatu, SP (Nota Científica). Ciência Animal Brasileira, v. 10, n. 1, p. 349-354, jan./mar. 2009.

McDONNELL, P.A.; SCOTT, K.G.; TEOH, D.A.; OLSON, M.E.; UPCROFT, J.A.; UPCROFT, P.; BURET, A.G. Giardia duodenalis trophozoites isolated from a parrot (Cacatua galerita) colonize the small intestinal tracts of domestic kittens and lambs. Veterinary Parasitology, v. 111, n. 1, p. 31-46, 2003.

O'DONOGHUE, P.J. Cryptosporidium and cryptosporidiosis in man and animals. Internationsl Journal for Parasitology, 25, p.139-195, 1995.

RUPLEY, A.E. Manual de Clínica Aviária. São Paulo:
Editora Roca, 2000, p. 310-311.

SCHARRA, D.M.F. Coccidiose. Disponível em http://www.tecnoweb.com.br/milward/html/cocciodiose.ht $\underline{\text { m. }}$ Acesso em 12 de junho de 2007.

SILVA, A. S.; MAHL, D. L.; SOARES, J. F.; FACCIO, L.; DAU, S. L.; ZANETTE, R. A.; MONTEIRO, S. G. Parasitismo Por Isospora sp. Em Agapornis fischeri (Pássaro-do-Amor) Criados Em Cativeiro No Brasil. Caderno de Pesquisa Série Biologia, Santa Cruz do Sul, v. 21, n. 1, Jan-May, p. 53-57, 2009.

SOULSBY, E.J.L. Helminths, Arthropods and Protozoa of Domesticated Animals, 7 ed. BailliéreTindall, London, 868p., 1986.

STRETER, V.; VARGA, I. Cryptosporidiosis in birds-a review. Veterinary Parasitology. 87, 4, p.261-279, 2000.

THADEI, C. L. Coccidioses. Disponível em < http://www.saudeanimal.com.br/artig121.htm >. Acesso em 09 de junho de 2007.

THOMPSON, R.C. Giardiasis as a re-emerging infectious disease and its zoonotic potential. International Journal of Parasitology, v. 30, p. 1259-1267, 2000.

TSAI, S. S. et al. Histopathological survey of protozoa, helminths andacarids of imported and local psittacine and passerine birds in Japan. Japanese Journal of Veterinary Research, v. 40, p. 161-174, 1992.

UPCROFT, J.A.; McDONNELL, P.A.; GALLAGHER, A.N.; CHEN, N. UPCROFT, P. Lethal Giardia from a wild-caught sulphur-crested cockatoo (Cacatua galerita) established in vitro chronically infects mice. Parasitology, v. 114, p. 407-412, 1997. 